\title{
Mitral valve repair in heart failure: Five-year follow-up from the mitral valve replacement stratum of the Acorn randomized trial
}

\author{
Michael A. Acker, MD, ${ }^{a}$ Mariell Jessup, MD, ${ }^{a}$ Steven F. Bolling, MD, ${ }^{b}$ Jae Oh, MD, ${ }^{c}$ \\ Randall C. Starling, MD, ${ }^{\mathrm{d}}$ Douglas L. Mann, MD, ${ }^{\mathrm{e}}$ Hani N. Sabbah, PhD, ${ }^{\mathrm{f}}$ Richard Shemin, MD, ${ }^{\mathrm{g}}$ \\ James Kirklin, MD, ${ }^{\mathrm{h}}$ and Spencer H. Kubo, $\mathrm{MD}^{\mathrm{i}}$
}

Objective: The study objective was to evaluate the long-term (5-year) safety and efficacy of mitral valve surgery with and without the CorCap cardiac support device (Acorn Cardiovascular, St Paul, Minn) in patients with dilated cardiomyopathy and New York Heart Association class II-IV heart failure.

Background: The Acorn trial provided a unique opportunity to assess the long-term safety and efficacy of mitral valve surgery because clinical visits and echocardiograms (read by a core laboratory) were completed for 5 years of follow-up. Further, this study provided follow-up data on the long-term effect of the CorCap cardiac support device as an adjunct to mitral valve surgery.

Methods: From the original Acorn trial ( $\mathrm{n}=300$ patients), 193 patients were enrolled in the mitral valve repair/ replacement stratum. A total of 102 were randomized to mitral valve surgery alone (control group) and 91 were randomized to mitral valve surgery with implantation of the CorCap cardiac support device (treatment group). Patients were followed up for 5 years.

Results: As previously reported, 30-day operative mortality was only $1.6 \%$. At 5 years, the total mortality was $30 \%$ with an average annual mortality rate of approximately $6 \%$ per year. The effects of mitral valve surgery led to a progressive decrease in left ventricular end-diastolic and end-systolic volumes, which were highly significant at all time points. At the end of 5 years, there was an average reduction in left ventricular end-diastolic volume of $75 \mathrm{~mL}$, which represents a $28 \%$ reduction from baseline. During 5 years of follow-up, 29 patients had recurrent mitral regurgitation and 5 patients underwent repeat mitral valve surgery. The addition of the CorCap device led to greater decreases in left ventricular end-diastolic volume (average difference of $16.5 \mathrm{~mL}$; $P=.05)$, indicating that the CorCap device had an additive effect to the mitral valve operation.

Conclusions: This study demonstrates long-term improvement in left ventricular structure and function after mitral valve surgery for up to 5 years. These data provide evidence supporting mitral valve repair in combination with the Acorn CorCap device for patients with nonischemic heart failure with severe left ventricular dysfunction who have been medically optimized yet remain symptomatic with significant mitral regurgitation. (J Thorac Cardiovasc Surg 2011;142:569-74)

\section{Supplemental material is available online.}

Mitral regurgitation (MR) is a common finding in patients with heart failure and dilated cardiomyopathy. ${ }^{1,2}$ The presence of MR is associated with a poor prognosis,

\footnotetext{
From the University of Pennsylvania, ${ }^{\text {a }}$ Philadelphia, Pa; University of Michigan, ${ }^{\mathrm{b}}$ Ann Arbor, Mich; Mayo Clinic, ${ }^{\mathrm{c}}$ Rochester, Minn; Cleveland Clinic Foundation, ${ }^{\mathrm{d}}$ Cleveland, Ohio; Baylor College of Medicine, ${ }^{\mathrm{e}}$ Houston, Tex; Henry Ford Hospital, ${ }^{\mathrm{f}}$ Detroit, Mich; University of California, ${ }^{\mathrm{g}}$ Los Angeles, Los Angeles, Calif; University of Alabama at Birmingham, ${ }^{\mathrm{h}}$ Birmingham, Ala; and Acorn Cardiovascular, ${ }^{\mathrm{i}}$ St Paul, Minn.

Supported by a grant from Acorn Cardiovascular, St Paul, Minnesota.

Disclosures: Authors have nothing to dislose with regard to commercial support.

Received for publication Feb 26, 2010; revisions received Sept 13, 2010; accepted for publication Oct 24, 2010; available ahead of print Jan 27, 2011.

Address for reprints: Michael A. Acker, MD, Hospital of the University of Pennsylvania, Cardiothoracic Surgery, 3400 Spruce St, Philadelphia, PA 19104-6070. 0022-5223/ $\$ 36.00$

Copyright (c) 2011 by The American Association for Thoracic Surgery doi:10.1016/j.jtcvs.2010.10.051
}

likely because of the contributions of chronic volume overload to progressive ventricular remodeling, ${ }^{3-5}$ which is characterized by the process of ventricular dilatation and a change from a conical to a spherical shape. Mitral valve repair (MVr) with ring annuloplasty has been proposed as a surgical treatment, and several studies have shown that the procedure is safe and often associated with long-term benefit and/or survival. ${ }^{6-13}$ However, these studies have been retrospective, single-center, or lack core laboratory echocardiographic long-term follow-up. An additional concern is that ring annuloplasty does not fully address all of the pathophysiologic mechanisms of functional MR (eg, ventricular dilation, annular dilation, and leaflet tethering), which may contribute to reports suggesting a variable rate of recurrent MR. ${ }^{14-16}$

The mitral valve replacement (MVR) stratum of the Acorn randomized trial provides a unique opportunity to assess the clinical role of MVr surgery in heart failure. ${ }^{17,18}$ As reported previously, the study was a multicenter and 


\author{
Abbreviations and Acronyms \\ $\mathrm{ACE}=$ angiotensin-converting enzyme \\ CSD = cardiac support device \\ $\mathrm{LV}=$ left ventricular \\ $\mathrm{MR}=$ mitral regurgitation \\ $\mathrm{MV}=$ mitral valve \\ $\mathrm{MVr}=$ mitral valve repair \\ $\mathrm{MVR}=$ mitral valve replacement
}

prospective evaluation of 193 patients who had $\mathrm{MVr}$ surgery and annual echocardiograms through 5 years of follow-up assessed by a core laboratory. ${ }^{19}$ Further, half of the patients were randomized to concomitant implantation of the Acorn CorCap cardiac support device (CSD; Acorn Cardiovascular, St Paul, Minn), which has been shown in experimental and clinical studies to improve ventricular size and shape. ${ }^{20,21}$ Thus, this study also provides longterm data on the potential additive benefits of passive containment with a CSD to MVr surgery.

\section{METHODS}

The Acorn trial was a prospective, randomized, and controlled evaluation of the CorCap CSD. ${ }^{17,18}$ The study enrolled 300 patients with dilated cardiomyopathy and heart failure into 2 strata. Patients who had clinically significant MR and an indication for MVr surgery were enrolled in the MVR surgery stratum $(n=193$ patients $)$ and then randomized to treatment (mitral valve $[\mathrm{MV}]$ surgery plus CSD, $\mathrm{n}=91$ ) or control (MVr surgery alone, $\mathrm{n}=102$ ). Patients without a clinical indication for MVr surgery were enrolled in the no-MVR surgery stratum $(n=107$ patients) and are not discussed further in this report.

Patients were eligible for the MVR stratum if they had New York Heart Association class II-IV heart failure and were between the ages of 18 and 80 years. All patients had a left ventricular (LV) ejection fraction of $45 \%$ or less and LV dilation (LV end-diastolic dimension $\geq 60 \mathrm{~mm}$ or an LV end-diastolic dimension index $\geq 30 \mathrm{~mm} / \mathrm{m}^{2}$ ). Patients received an optimal medication regimen that included an angiotensin-converting enzyme (ACE) inhibitor (or angiotensin receptor blocker if ACE intolerant) and a beta-blocker (for at least 3 months). Specific exclusion criteria were summarized previously. ${ }^{17,18}$ The institutional review board of each center approved the study protocol and all patients gave written informed consent.

Baseline testing included blood tests, transthoracic echocardiogram, quality of life evaluation with Minnesota Living with Heart Failure questionnaire and the short-form 36 questionnaire, a 6-minute walk test, and an exercise test to measure peak oxygen consumption. These tests were followed only to the common closing date and were previously reported. ${ }^{18}$ Randomization to treatment or control groups was stratified by site and based on random permuted blocks.

MV surgery was performed using standard operative techniques including cardiopulmonary bypass and an undersized MV annuloplasty ring placement or valve replacement. CorCap CSD implant techniques have been summarized previously. ${ }^{22}$

The CorCap CSD is a fabric mesh device that is implanted around the heart to provide circumferential diastolic support and reduce LV wall stress. In animal models of heart failure, the CSD resulted in benefical changes in LV structure and function, a decrease in myocyte hypertrophy, improvements in myocyte shortening, decreased interstitial fibrosis, and a reversal of fetal gene expression. ${ }^{21,22}$
Follow-up evaluation was completed at 3 months, 6 months, and then annually until 5 years and included data on deaths, hospitalizations, adverse events, and major cardiac procedures. Echocardiograms were obtained at annual visits and were read by the Core Laboratory at the Mayo Clinic, which was blinded to clinical and randomization data. All efficacy and safety end points were analyzed according to the intention-to-treat principle. Cumulative survival curves for the risk of death and the time to recurrent MR and repeat MV surgery were constructed according to the Kaplan-Meier method. For continuous variables, comparisons of changes from baseline to 60 months were evaluated with a longitudinal regression analysis, a mixed effects model in which follow-up visit was the repeated measure and the baseline value of the response was considered as a covariate.

\section{RESULTS \\ Patient Population}

As previously described, ${ }^{19}$ the MVR stratum included 193 patients (54\% female) with a mean age of $53.4 \pm$ 12.6 years. Baseline New York Heart Association classes were II $(23.3 \%)$, III $(71.5 \%)$, and IV $(5.2 \%)$. The etiology of heart failure was idiopathic cardiomyopathy $(60.6 \%)$, valvular heart disease $(17.1 \%)$, and ischemic heart disease $(6.2 \%)$. At baseline, patients had evidence of ventricular remodeling with a mean LV end-diastolic volume of $270.1 \pm$ $100.3 \mathrm{~mL}, \mathrm{LV}$ end-diastolic dimension of $69.7 \pm 8.8 \mathrm{~mm}$, and LV ejection fraction of $23.9 \% \pm 89 \%$. In addition, patients demonstrated functional limitations with a Minnesota Living with Heart Failure questionnaire score of $58.8 \pm$ 23.9 units, a short-form 36 physical functioning score of $37.1 \pm 22.9$ units, a 6-minute walk test of $344.3 \pm$ $90.4 \mathrm{~m}$, and a peak oxygen consumption of $14.1 \pm 4.3$ $\mathrm{mL} \cdot \mathrm{kg}^{-1} \cdot \min ^{-1}$. Optimal medical therapy included ACE inhibitors (97.4\%) and beta-blockers (80.3\%).

Baseline severity of MR was measured in 2 different laboratories. Echocardiograms reviewed by the individual sites' echocardiography laboratories were used to identify potential patients. All patients had significant MR (MR grade $\geq 3+$ ) and a clinical indication for MVR surgery based on site reading, in conjunction with other studies such as contrast ventriculograms and transesophageal echocardiograms. All echocardiograms were also read in a central core laboratory; these values were used solely for tracking end points. On the basis of the core laboratory readings, baseline MR grade was 0 in $14(7.4 \%)$ patients, $1+$ in $20(10.6 \%)$ patients, $2+$ in $44(23.3 \%)$ patients, $3+$ in $49(25.9 \%)$ patients, and $4+$ in $62(32.8 \%)$ patients.

\section{Mitral Surgery}

For the intent-to-treat analysis, 9 of the 193 patients did not undergo MV surgery (5 patients refused, 1 patient died before surgery, and it was surgically decided for 3 patients). Most patients ( $\mathrm{n}=155$ patients; $84.2 \%$ ) received an undersized mitral annuloplasty ring (ring size of $28 \mathrm{~mm}$ used in $82 \%$ of patients). There were $29(15.8 \%)$ patients who underwent MVR including 4 patients who were converted from repair to replacement at the time of the original 


\section{Mortality / MVR: June 2008}

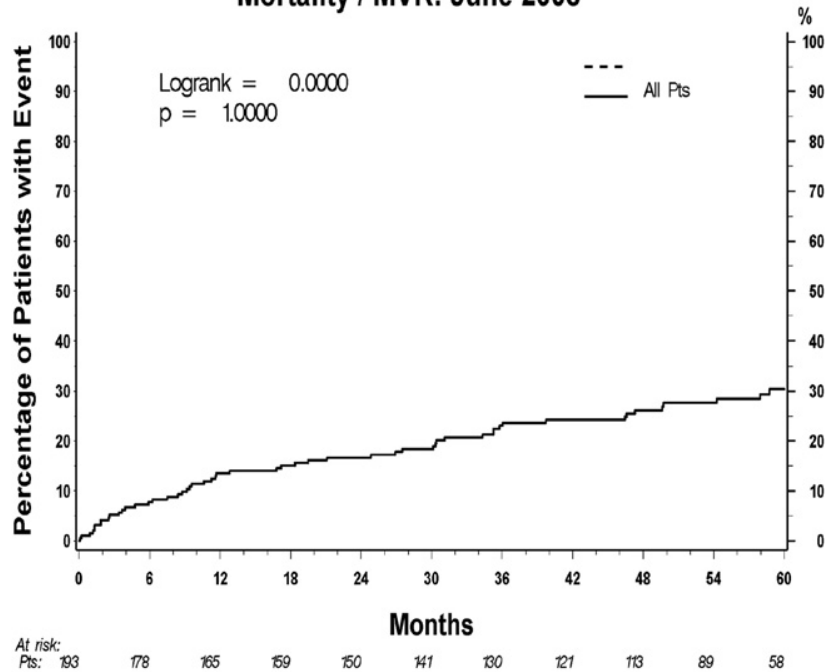

FIGURE 1. Kaplan-Meir survival curve for the entire group of 193 patients in the MV surgery stratum.

operation. In the other patients, surgeons chose replacement if there were primary valvular abnormalities (eg, rheumatic disease) or when it was believed that repair would not yield a satisfactory result. During MVR surgery, most patients had preservation of both anterior and posterior chordal structures.

The Kaplan-Meier survival curve for the overall group is shown in Figure 1. As previously reported, the 30-day operative mortality was $1.6 \%$ ( 3 deaths). At 5 years, the total mortality was $30 \%$ with an average annual mortality rate of approximately $6 \%$ per year.

\section{Cardiac Structure and Function}

The effects of MVr surgery on LV structure and function are summarized in Figures 2 and 3. There was a progressive decrease in LV end-diastolic volume (Figure 2, $A$ ) and LV end-systolic volume (Figure 2, B) that was highly significant at all time points through 5 years. At the end of the follow-up, there was an average reduction in LV enddiastolic volume of $75 \mathrm{~mL}$, which represents a $28 \%$ reduction from baseline. There were also improvements in LV ejection fraction (Figure 3), which reached statistical significance at 18 months and remained significantly improved from baseline at 24, 36, 48, and 60 months.

During 5 years of follow-up, 29 patients had recurrent MR (defined as 3 or $4+$ MR by the core echocardiography laboratory readings) and 5 patients underwent repeat MV surgery. Figure 4 summarizes the Kaplan-Meier estimate of the freedom from MR or repeat MV surgery. At 5 years, the cumulative estimate of 3 to $4+$ MR or repeat MV surgery was $19 \%$. There was no difference in overall survival or degree of reverse remodeling between patients with MVr or MVR at 5 years.
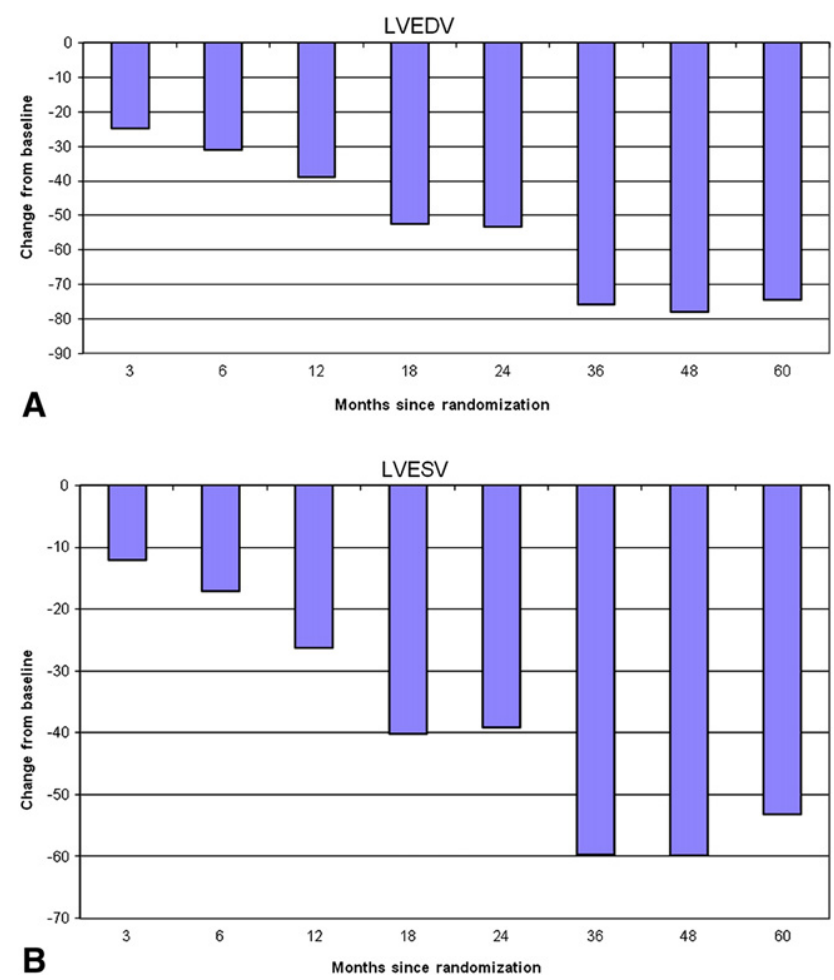

FIGURE 2. (A) Reduction in left ventricular end-diastolic volume (LVEDV) for the entire group of 193 patients in the mitral valve surgery stratum. There was aggressive and significant reduction in LVEDV at 1 , 2 , and 3 years, which remained stable at years 4 and 5 consistent with reverse remodeling. (B) Reduction in left ventricular end-systolic volume (LVESV) for entire group of 193 patients in the mitral valve surgery stratum. Similar to the changes in LVEDV, there was a progressive and significant decrease in LVESV at 1, 2, and 3 years, which remained stable at years 4 and 5 .

\section{Surgery With CSD}

The effects of the concomitant implantation of the CorCap CSD to MV surgery were assessed by comparing the treatment group (MVr plus CSD) with the control group

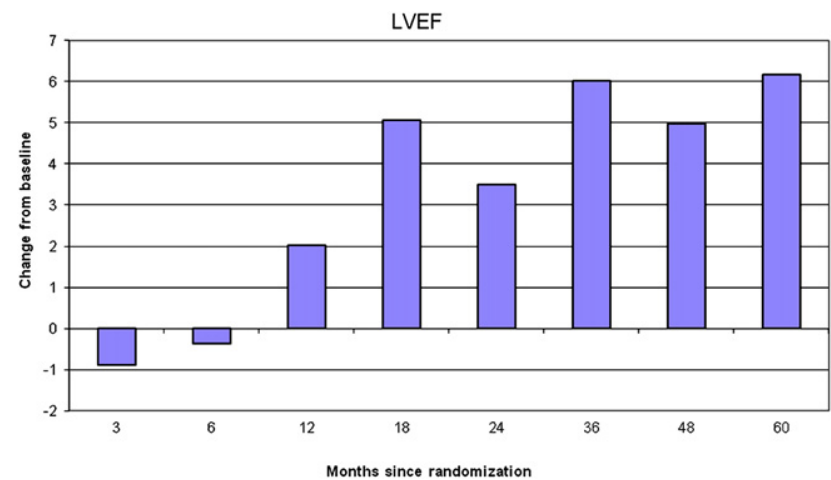

FIGURE 3. Change in left ventricular ejection fraction ( $L V E F)$ for the entire group of 193 patients in the mitral valve surgery stratum. There was an improvement in left ventricular ejection fraction, which was significant at 18 months and remained so for 5 years. 
Time to 3/4+ MR or Repeat MVR Combined: June 2008, MVR Stratum

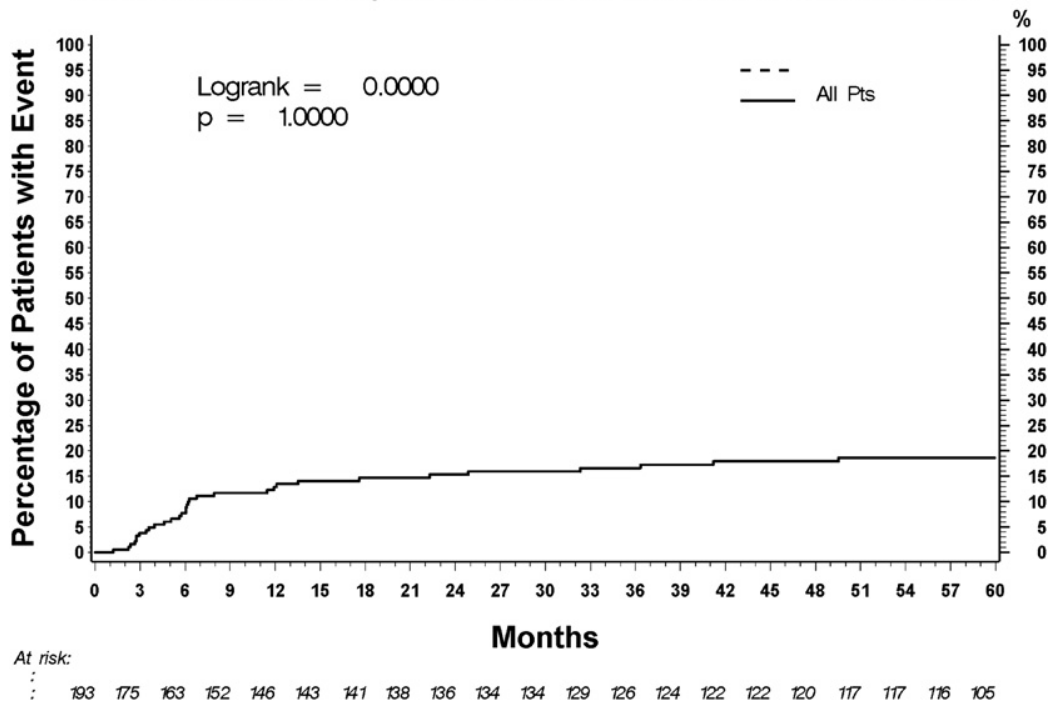

FIGURE 4. Kaplan-Meir estimate of freedom from $3 / 4+$ mitral regurgitation $(M R)$ or redo mitral valve replacement $(M V R)$ combined.

(MVr alone). There was no significant difference in survival or the frequency of recurrent MR between the treatment and control groups. Compared with the control group, the treatment group (MV surgery plus CSD) had fewer cardiac transplants (11 vs 12), fewer LV assist devices (5 vs 6), and fewer biventricular pacemakers (14 vs 19), but none of these differences was statistically significant.

The effects of the CSD on LV size and shape are shown in Figures 5 and 6. For LV end-diastolic volume (Figure 5), the control group (MV surgery alone) demonstrated a progressive decrease in LV end-diastolic volume, suggesting that

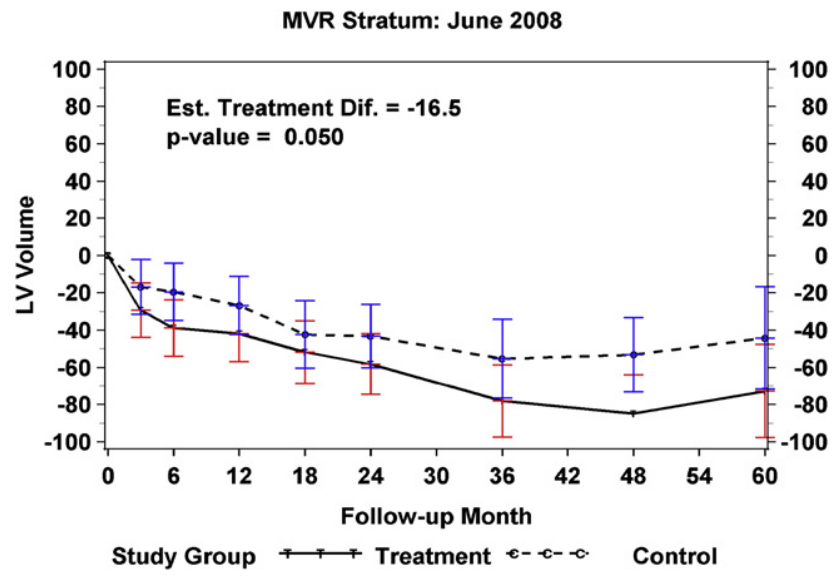

FIGURE 5. Reduction in left ventricular end-diastolic volume for the control group (no cardiac support device) and treatment group (with cardiac support device). Treatment group (mitral valve surgery and cardiac support device) had significantly greater decrease in left ventricular end-diastolic volume compared with control (mitral valve surgery alone) throughout the 5 years of follow-up $(P=.05) . M V R$, Mitral valve replacement; $L V$, left ventricular.
MV surgery by itself can result in reverse remodeling. However, the treatment (MV surgery and CSD) group had a significantly greater decrease in LV end-diastolic volume that persisted throughout the 5 years of follow-up (average difference $=16.5 \mathrm{~mL} ; P=.05$ ), indicating that the CorCap device had an additive effect to MV surgery. Similar additive benefits were observed with LV end-systolic volume.

Sphericity index (Figure 6) is a reflection of the shape of the LV (length/width ratio) so that a higher sphericity index indicates a more ellipsoidal ventricle. Sphericity index increased in the control group, suggesting that MV surgery by itself can result in an improvement in LV shape. The

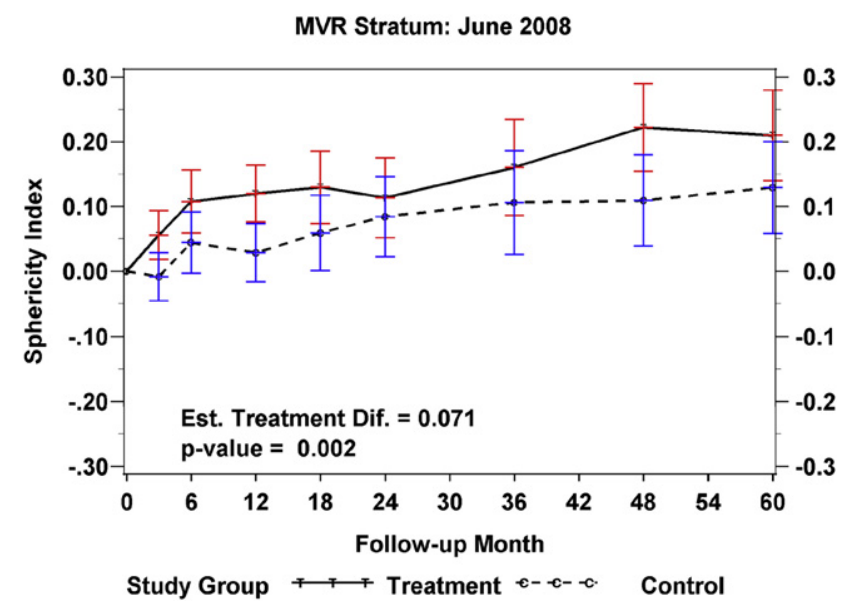

FIGURE 6. Sphericity index for the control group (no cardiac support device) and treatment group (with cardiac support device). The treatment group (mitral valve surgery and cardiac support device) had significantly greater increase in sphericity index when compared to control group (mitral valve surgery alone) $(P=.002)$. MVR, Mitral valve replacement. 
TABLE 1. Patients experiencing serious adverse events by treatment group; mitral valve surgery stratum

\begin{tabular}{|c|c|c|c|c|c|}
\hline & \multicolumn{4}{|c|}{ MVR stratum } & \multirow[b]{3}{*}{$P$ value* } \\
\hline & \multicolumn{2}{|c|}{ Treatment } & \multicolumn{2}{|c|}{ Control } & \\
\hline & No. & $\%$ & No. & $\%$ & \\
\hline Allergic response & 4 & 4.4 & 1 & 1.0 & .19 \\
\hline Arrhythmia & 41 & 45.1 & 48 & 47.1 & .89 \\
\hline Bleeding & 9 & 9.9 & 16 & 15.7 & .29 \\
\hline Hemodynamic compromise & 66 & 72.5 & 62 & 60.8 & .095 \\
\hline Hepatic compromise & 2 & 2.2 & 0 & 0.0 & .22 \\
\hline Infection/pneumonia & 39 & 42.9 & 38 & 37.3 & .46 \\
\hline Myocardial infarction & 0 & 0.0 & 1 & 1.0 & 1.00 \\
\hline Neurologic deficit/stroke & 17 & 18.7 & 9 & 8.8 & .057 \\
\hline Peripheral thrombus/embolism & 3 & 3.3 & 2 & 2.0 & .67 \\
\hline Pulmonary compromise & 30 & 33.0 & 21 & 20.6 & .072 \\
\hline Pulmonary embolism & 2 & 2.2 & 2 & 2.0 & 1.00 \\
\hline Renal compromise & 13 & 14.3 & 9 & 8.8 & .26 \\
\hline Other & 50 & 54.9 & 59 & 57.8 & .77 \\
\hline Any of the above SAE & 83 & 91.2 & 93 & 91.2 & 1.00 \\
\hline No. of patients & & & & 02 & \\
\hline
\end{tabular}

$\overline{M V R}$, Mitral valve replacement; $S A E$, serious adverse event. ${ }^{*} P$ values generated from Fisher's exact test.

treatment group had a significantly greater increase in sphericity index that persisted throughout 5 years of follow-up (average difference $=0.071$ units; $P=.002$ ), indicating that the CorCap device had an additive effect to MV surgery.

\section{Adverse Events}

Table 1 summarizes the number of patients experiencing a serious adverse event at any time during follow-up. Overall, $82.4 \%$ of the treatment group and $79.4 \%$ of the control group had a serious adverse event. The number of patients and types of adverse events were not statistically different between the 2 groups. There were no clinical cases of constriction in any patient. The vast majority of serious adverse events occurred immediately after surgery and were commonly observed in patients undergoing cardiac surgery.

\section{DISCUSSION}

Treatment options for functional MR in general have been limited. There is no consistent evidence that standard medical therapies, including ACE inhibitors and beta-blockers, have long-term benefit on MR severity or outcomes. Despite evidence that MV surgery can reduce MR, broad scale adoption of this intervention has been limited by concerns of a high perioperative mortality rate, rate of recurrent MR, lack of long-term benefit on the remodeling process, and overall survival. The present study directly addressed many of these concerns and demonstrated that MVr surgery was safe with a low operative mortality rate, low 5-year recurrent rate of MR $(19 \%)$, and documented long-term benefits in LV structure and function. Whether these results, in patients with primarily nonischemic heart failure, can be expanded to ischemic cardiomyopathy is unknown.

The MV stratum (MVR) of the Acorn Clinical Trial provided a unique opportunity to evaluate some of the common questions regarding the role and clinical impact of $\mathrm{MVr} /$ MVR surgery in patients with heart failure. The strength of this current data set is that the study was conducted as a multicenter, prospective trial of 193 patients with heart failure who had poor ventricular function undergoing MV surgery, with clinical and core laboratory echocardiographic follow-up extending to 5 years. Principal findings reported earlier ${ }^{19}$ included a mortality rate of only $1.6 \%$, one of the lowest mortality rates of any series. $8,10,12$ Especially noteworthy is that this perioperative mortality rate represents the outcome of nearly 30 different centers (Appendix E1). One-, 2-, and 5-year survivals were $86.5 \%, 85.2 \%$, and $70 \%$, respectively. MV insufficiency was reduced from 2.7 at baseline to 0.59 at 18 months. At 5 years, freedom from reoperation for 3 to $4+$ MR was $81 \%$. There was strong evidence of reversal of ventricular remodeling as a result of elimination of MV insufficiency alone. Specifically, there was a significant decrease in both LV end-diastolic and end-systolic volume, which remained significant out to 5 years. The sphericity index increased and remained significant out to 5 years, consistent with a return to a more ellipsoid shape. There was also a significant increase in LV ejection fraction over baseline, seen at 18 months and maintained out to 5 years. LV mass decreased significantly at 2 years. ${ }^{19}$ Finally, the baseline New York Heart Association class of 2.8 was reduced significantly to 2.2 at 2 years. ${ }^{19}$ This current report underscores the shorter term results and documents that the benefits seen at 2 years are maintained after 5 years.

Recent reports from the Cleveland Clinic suggest that the recurrence rate of ischemic mitral insufficiency after repair is in the $30 \%$ to $40 \%$ range. ${ }^{14,15}$ Early recurrence of mitral insufficiency, reported by McGee, ${ }^{14}$ Mihaljevic, ${ }^{15}$ and their colleagues, as well as others, has been noted for patients with ischemic heart failure after coronary artery bypass surgery and annuloplasty ring. These results stand in contrast to minimal recurrent MR as reported by Braun and associates, ${ }^{6,23}$ who demonstrated that the combination of $\mathrm{MVr}$ with a small complete rigid annuloplasty ring and coronary artery bypass grafting results in significant decrease of LV end-diastolic dimensions for up to 4 years after surgery.

In addition, Fattouch and associates ${ }^{24}$ have recently demonstrated in a randomized study of coronary artery bypass alone versus coronary artery bypass and $\mathrm{MVr}$ that the addition of MVr improved postoperative New York Heart Association functional class, ventricular remodeling, decreased pulmonary arterial pressures, and led to a decrease in hospitalization for heart failure. These same studies also show low operative mortality rates for combined MV surgery and coronary artery bypass procedures in patients with 
significant LV dysfunction and advanced heart failure symptoms.

$\mathrm{We}^{25}$ have recently completed a comprehensive analysis of echocardiograms from these patients. Compared with patients without MR recurrence, patients with recurrent MR had greater distal mitral anterior leaflet angle, greater basal mitral anterior leaflet angle, greater coaptation depth and tenting area, larger LV volumes, and worse LV ejection fraction. Multivariable analysis identified postoperative distal mitral anterior leaflet angle as the best predictor of MR recurrence. These data suggest that tethering of the distal anterior leaflet secondary to LV dilation is the primary mechanism of recurrent MR after mitral annuloplasty in idiopathic cardiomyopathy.

Importantly, the addition of the Acorn CorCap CSD led to a significant incremental improvement over MVr alone in terms of LV size and shape for up to 5 years. When implanted as a stand-alone intervention, the CorCap device has been shown to improve LV structure and function in 3 different models of heart failure. ${ }^{21,26}$ Moreover, we have previously reported 3-year follow-up data from the CSD only stratum of the Acorn trial that showed a statistically significant effect on a composite end point, a reduction in major cardiac procedures, and a persistent benefit in LV structure and function. ${ }^{27}$ The current 5 -year data provide the first evidence that benefits associated with the CorCap device are durable and sustained through 5 years of follow-up. Because the implantation of the CorCap CSD adds only 20 to 30 minutes of surgery time and minimal additional risk, the incremental benefit on LV size and shape appear to be a valuable adjunct to MV surgery.

In summary, this study demonstrates long-term improvement in LV structure and function after MV surgery, with and without the addition of the Acorn CSD, for up to 5 years. These data provide evidence supporting MVr in combination with the Acorn CorCap device for patients with nonischemic heart failure and severe LV dysfunction who have been medically optimized yet remain symptomatic with significant MR.

\section{References}

1. Otto CM. Evaluation and management of chronic mitral regurgitation. $N$ Engl J Med. 2001;345:740-6.

2. Robbins JD, Maniar PB, Cotts W, Parker MA, Bonow RO, Gheorghiade M. Prevalence and severity of mitral regurgitation in chronic systolic heart failure. Am J Cardiol. 2003;91:360-2.

3. Koelling TM, Aaronson KD, Cody RJ, Bach DS, Armstrong WF. Prognostic significance of mitral regurgitation and tricuspid regurgitation in patients with left ventricular systolic dysfunction. Am Heart J. 2002;144:524-9.

4. Robbins JD, Maniar PB, Cotts W, Parker MA, Bonow RO, Gheorghiade M. Prevalence and severity of mitral regurgitation in chronic systolic heart failure. Am J Cardiol. 2003;91:360-2.

5. Trichon BH, Felker GM, Shaw LK, Cabell CH, O'Connor CM. Relation of frequency and severity of mitral regurgitation to survival among patients with left ventricular systolic dysfunction and heart failure. Am J Cardiol. 2003;91:538-43.

6. Braun J, Bax JJ, Versteegh MI, Voigt PG, Holman ER, Klautz RJ, et al. Preoperative left ventricular dimensions predict reverse remodeling following restrictive mitral annuloplasty in ischemic mitral regurgitation. Eur J Cardiothorac Surg. 2005;847-53.

7. Bach DS, Bolling SF. Improvement following correction of secondary mitral regurgitation in end-stage cardiomyopathy with mitral annuloplasty. Am J Cardiol. 1996;78:966-9.

8. Badhwar V, Bolling SF. Mitral valve surgery in the patient with left ventricular dysfunction. Semin Thorac Cardiovasc Surg. 2002;14:133-6.

9. Bax JJ, Braun J, Somer ST, Klautz R, Holmaner ER, Versteegh MI, et al. Restrictive annuloplasty and coronary revascularization in ischemic mitral regurgitation results in reverse left ventricular remodeling. Circulation. 2004;110(suppl 1): II103-8.

10. Bishay ES, McCarthy PM, Cosgrove DM, Hoercher KJ, Smedira NG, Mukherjee P, et al. Mitral valve surgery in patients with severe left ventricular dysfunction. Eur J Cardiothorac Surg. 2000;17:213-21.

11. Bolling SF, Pagani FD, Deeb GM, Bach DS. Intermediate-term outcome of mitral reconstruction in cardiomyopathy. J Thorac Cardiovasc Surg. 1998;115:381-6; discussion 387-8.

12. Gummert JF, Rahmel A, Bucerius J, Onnasch J, Doll N, Walther T, et al. Mitral valve repair in patients with end stage cardiomyopathy: who benefits? Eur J Cardiothorac Surg. 2003;23:1017-22; discussion 1022.

13. Romano MA, Bolling SF. Update on mitral repair in dilated cardiomyopathy. J Card Surg. 2004;19:396-400.

14. McGee EC, Gillinov AM, Blackstone EH, Rajeswaran J, Cohen G, Najam F, et al. Recurrent mitral regurgitation after annuloplasty for functional ischemic mitral regurgitation. J Thorac Cardiovasc Surg. 2004;128:916-24.

15. Mihaljevic T, Lam BK, Rajeswaran J, Takagaki M, Lauer MS, Gillinov AM, et al. Impact of mitral valve annuloplasty combined with revascularization in patients with functional ischemic mitral regurgitation. JAm Coll Cardiol. 2007;49:2191-201.

16. Spoor MT, Geltz A, Bolling SF. Flexible versus nonflexible mitral valve rings for congestive heart failure: differential durability of repair. Circulation. 2006; 114(suppl 1):I67-71

17. Mann DL, Acker MA, Jessup M, Sabbah HN, Starling RC, Kubo SH, on behalf of Acorn Investigators and Study Coordinators. Rationale, design and methods for a pivotal randomized clinical trial for the assessment of a cardiac support device in patients with New York Heart Association Class III-IV heart failure. J Card Fail. 2004;10:185-92.

18. Mann DL, Acker MA, Jessup M, Sabbah HN, Starling RC, Kubo SH. Role of multicenter randomized clinical trial for the assessment of a cardiac support device (CSD) in patients with heart failure. Ann Thorac Surg. 2007;84:1226-35.

19. Acker MA, Bolling S, Shemin R, Kirklin J, Oh JK, Mann DL, et al. Mitral valve surgery in heart failure: insights from the Acorn Clinical Trial. J Thorac Cardiovasc Surg. 2006;132:568-77.

20. Sabbah HN, Sharov VG, Gupta RC, Mishra S, Rastogi S, Undrovinas AI, et al. Reversal of chronic molecular and cellular abnormalities due to heart failure by passive mechanical ventricular containment. Circ Res. 2003;93:1095-101.

21. Sabbah HN. Global left ventricular remodeling with the Acorn Cardiac Support Device: hemodynamic and angiographic findings in dogs with heart failure. Heart Fail Rev. 2005;10:109-15.

22. Oz MC, Konertz WF, Kleber FX, Mohr FW, Gummert JF, Ostermeyer J, et al. Global surgical experience with the Acorn cardiac support device. J Thorac Cardiovasc Surg. 2003;126:983-91.

23. Braun J, van de Veire NR, Klautz RJ, Versteegh MI, Holman ER, Westenberg JJ, et al. Long term follow-up confirms left ventricular reverse remodeling following restrictive mitral annuloplasty and CABG in ischemic MR. Presented at: 87th Annual Meeting of The American Association for Thoracic Surgery; May 5-9, 2007; Washington, DC.

24. Fattouch K, Guccione F, Muscarelli M, Navarra E, Calvaruso D, Speziale G, Ruvolo G. POINT: Efficacy of adding mitral valve restrictive annuloplasty to coronary artery bypass grafting in patients with moderate ischemic mitral valve regurgitation: a randomized trial. J Thorac Cardiovasc Surg. 2009;138:278-85.

25. Pui-Lee A, Acker M, Kubo SH, Bolling SF, Park SE, Bruce CJ, et al. Mechanisms of recurrent functional mitral regurgitation after mitral valve repair in nonischemic dilated cardiomyopathy: importance of distal anterior leaflet tethering. Circulation. 2009;119:2606-14.

26. Blom AS, Mukherjee R, Pilla JJ, Lowry AS, Yarbrough WM, Mingoia JT, et al. Cardiac support device modifies left ventricular geometry and myocardial structure after myocardial infarction. Circulation. 2005;112:1274-83.

27. Starling RC, Jessup M, Oh JK, Sabbah HN, Acker MA, Mann DL, et al. Sustained benefits of the CorCap Cardiac Support Device on left ventricular remodeling: three year follow-up results from the Acorn Clinical Trial. Ann Thorac Surg. 2007;84:1236-42. 


\section{APPENDIX E1. Clinical Centers}

Advocate Christ Medical Center, Hershey, Pa: W. Pae, J. Boehmer, P. Ulsh, K. McFadden; Royal Victoria Hospital/ McGill University, Montreal, Quebec, Canada: R. Cecere, N. Giannetti, C. Barber; St Louis University, St Louis, Mo: A. Aharon, P. Hauptman, M. Jacob; Stanford University Medical Center/Kaiser Permanente, Stanford, Calif: R. Robbins, M. Fowler, D. Weisshaar, A. Mullin, K. Town; University of Alabama at Birmingham, Birmingham, Ala: J. Kirklin, B. Rayburn, K. Harper; University of Florida/ Shands Hospital, Gainesville, Fla: E. Staples, J. Aranda, D. Leach; University of Maryland Medical Center, Baltimore, Md: J. Gammie, S. Gottlieb, J. Marshall; University of Michigan Hospital, Ann Arbor, Mich: S. Bolling, K. Aaronson, M. Jessup, P. Obriot; University of Minnesota Medical Center, Minneapolis, Minn: S. Park, L. Miller, J. Graziano; University of Pittsburgh Medical Center, Pittsburgh, Pa: Advocate Christ Medical Center, Oaklawn, Ill: M. Slaughter, M. Silver, T. George, H. Lonergan-Thomas; Albert Einstein College of Medicine, Bronx, NY: T. LeJemtel, M. Camacho, N. Cesare, P. Sicilia; Baylor College of Medicine/VAMC, Houston, Tex: E. Soltero, D. Mann, T. Lynch; Boston Medical Center, Boston, Mass: R. Shemin, G. Philippides, M. Cheney; Bryan LGH Heart Institute, Lincoln, Neb: E. Raines, S. Krueger, V. Norton; Cedars-Sinai Medical Center, Los Angeles, Calif: K. Magliato, S. Khan, L. Defensor, M. De Robertis, D. Gallegos; Cleveland Clinic Foundation, Cleveland, Ohio: N. Smedira, R. Starling, R. Schott, B. Gus; Columbia-Presbyterian Medical Center, New York, NY: N. Edwards, D. Mancini, K. Idrissi, J. Dimitui Vallarta; Duke University Medical Center, Durham, NC: C. Milano, S. Russell, S. Welsh, A. Skye, R. Larsen; Henry Ford Hospital, Detroit, Mich: R. Brewer, B. Czerska, K. Leszczynski, N. Wulbrecht; Hospital of the University of Pennsylvania, Philadelphia, Pa: M. Acker, M. Jessup, S. Baker, M. O'Hara; Jewish Hospital at University of Louis- ville, Louisville, Ky: R. Dowling, G. Bhat, L. Muncy, K. Daley; Nebraska Heart Institute, Lincoln, Neb: D. Gangahar, K. Ayala, L. Taylor; New England Medical Center at Tufts University, Boston, Mass: K. Khabbaz, D. DeNofrio, C. Grodman; Newark Beth Center, Hershey, Pa: W. Pae, J. Boehmer, P. Ulsh, K. McFadden; Royal Victoria Hospital/ McGill University, Montreal, Quebec, Canada: R. Cecere, N. Giannetti, C. Barber; St Louis University, St Louis, Mo: A. Aharon, P. Hauptman, M. Jacob; Stanford University Medical Center/Kaiser Permanente, Stanford, Calif: R. Robbins, M. Fowler, D. Weisshaar, A. Mullin, K. Town; University of Alabama at Birmingham, Birmingham, Ala: J. Kirklin, B. Rayburn, K. Harper; University of Florida/ Shands Hospital, Gainesville, Fla: E. Staples, J. Aranda, D. Leach; University of Maryland Medical Center, Baltimore, Md: J. Gammie, S. Gottlieb, J. Marshall; University of Michigan Hospital, Ann Arbor, Mich: S. Bolling, K. Aaronson, M. Jessup, P. Obriot; University of Minnesota Medical Center, Minneapolis, Minn: S. Park, L. Miller, J. Graziano; University of Pittsburgh Medical Center, Pittsburgh, Pa: K. McCurry, S. Murali, T. Ryan, D. Zaldonis; VA Medical Center, San Diego Health Care System, San Diego, Calif: M. Madani, R. Shabetai, C. Jaynes, R. Cremo, N. Gardetto; VA Medical Center Minneapolis, Minneapolis, Minn: H. Ward, I. Anand, J. Whitlock; Washington Hospital Center, Washington, DC: M. Dullum, B. Carlos, J. Richmond, C. Bither, W. Varmer.

Steering Committee: D. Mann (Principal Investigator), M. Acker, M. Jessup, H. N. Sabbah, R. Starling; Data and Safety Monitoring Committee: G. Francis (Chair), J. Neaton, D. Homans, C. O'Connor, W. Curtis. Clinical Events Review Committee: S. Goldstein (Chair), F. Spinale, J. Lindenfeld Israel, Newark, NJ: D. Goldstein, M. Zucker, J. Casida; Oschner Heart and Vascular Institute, New Orleans, La: C. Van Meter, M. Mehra, B. Harris; Penn State/Milton S. Hershey Medical Center, Hershey, Pa. 